\title{
DYNAMIC ANALYSIS OF COMPOSITE BEAMS WITH WEAK SHEAR CONNECTION SUBJECTED TO AXIAL LOAD
}

\author{
Ákos József LENGYeL \\ Departmrent of Applied Mechanics, University of Miskolc \\ H-3515 Miskolc-Egyetemváros, Miskolc, Hungary \\ mechlen@uni-miskolc.hu
}

[Received: March 26, 2017; Accepted: June 12, 2017]

\begin{abstract}
The paper provides a new analytical method for determining the eigenfrequences of composite beams with interlayer slip provided that the beam is subjected to an axial load. Application of the d'Alembert principle yields the equations of motion. The axial and rotary inertia are taken into account. This formulation leads to a general eigenvalue problem whose solution is illustrated by a numerical example.
\end{abstract}

Mathematical Subject Classification: 74H45, 74H55, 74K10

Keywords: Composite beam, interlayer slip, stability analysis, vibration analysis

\section{INTRODUCTION}

Layered composite structures, especially layered beams, are widely applied in building and bridge engineering since the advantages of the layers made of different elastic materials can be complement each other, while their disadvantages can be reduced or eliminated. Therefore it is very important to understand the mechanical behavior of the layered composite beams and the influence of the connection between the layers for the mechanical properties. In a number of industrial applications the layers of composite beams are joined to each other by different shear connectors such as nails, screws or rivets. Because of the elastic deformation of those connectors two phenomena can occur between the layers. In normal direction the layers can separate (it is called uplift) and in axial direction an interlayer slip can happen. In this paper it is assumed that the connection is perfect in normal direction, viz. uplift is not allowed, whilst the connection is imperfect in axial direction so interlayer slip can appear.

There are a lot of works in connection with composite beams with interlayer slip [1][18. The first studies were published in the 1950's 1, 2, 3]. The pioneering and most cited work is Newmark et al. 1]. They elaborated an analytical solution for composite beams with interlayer slip based on the Euler-Bernoulli beam theory. The problem was governed by a linear differential equation of second order in the longitudinal force resisted by the top element, and the other unknowns were the longitudinal force and 
the expression for moment along the beam. Girhammar and Gopu [5] proposed a formulation for the exact first- and second-order analyses of composite beam columns with partial shear interaction subjected to transverse and axial loading. Ecsedi and Baksa [6] also deduced the governing equation of the problem in terms of the slip and the vertical displacement.

There exist several works in connection with the dynamic analysis of composite beams with interlayer slip [7, 8, 9, 10, 11. An exact and an approximate analysis of composite members with partial interaction and subjected to general dynamic loading was presented by Girhammar and Pan [7]. Adam et al. [8] analysed the flexural vibration of composite beams with interlayer slip using the Euler-Bernoulli beam theory. The governing sixth order initial-boundary value problem was solved by separating the dynamic response in a quasi-static and in a complementary dynamic response. Heuer and Adam extended the previous model for composite beams made of piezoelectric materials in 9]. The partial differential equations and general solutions for the deflection and internal actions and the pertaining consistent boundary conditions were presented for composite Euler-Bernoulli members with interlayer slip subjected to general dynamic loading in [10]. Wu et al. [11 derived the governing differential equations of motion for the partial-interaction composite members with axial force. All these works neglected the influence of axial and rotary inertia.

The elastic stability problems of composite beams with weak shear connection were also investigated [12, 13, 14, 15, 16]. Challamel and Girhammar [12] analysed the lateral-torsional stability of vertically layered composite beams with interlayer slip based on a variational approach. An analytical method was presented for the delamination buckling using the Timoshenko beam theory by Chen and Qiao [13. Grognec et al. 14] utilized the Timoshenko beam theory as well. Schnabl and Planinc [15] presented a detailed analysis of the influence of boundary conditions and axial deformation on the critical buckling loads and the same authors took into account the effect of the transverse shear deformation on buckling [16].

In this paper the free vibration of layered composite beams with interlayer slip is investigated while an axial force is acting on the considered beam. During the formulation of the equations of motion axial and the rotary inertia is also taken into account. The results from papers by Lengyel and Ecsedi [17, 18, are compared with those deriving from the presented method.

\section{EquATions of MOtion}

The considered two-layer composite beam with interlayer slip is shown in Figure 1 . It is assumed that each layer separately follows the Euler-Bernoulli hypothesis and the load-slip relation for the flexible shear connection is a linear relationship. In the reference configuration, the composite beam occupies the $3 \mathrm{D}$ region $B=A \times$ $[0, L]$ generated by translating its symmetrical cross section $A$ along a rectilinear axis, orthogonal to the cross section. The cross-section $A$ is divided into two parts $A_{1}$ and $A_{2}$, that is $A=A_{1} \cup A_{2}$ and the common boundary $A_{1}$ and $A_{2}$ is denoted by $\partial A_{12}$. The components $B_{1}$ and $B_{2}$ are defined as $B_{i}=A_{i} \times[0, L], \partial B_{i}=\partial A_{i} \times[0, L]$, 

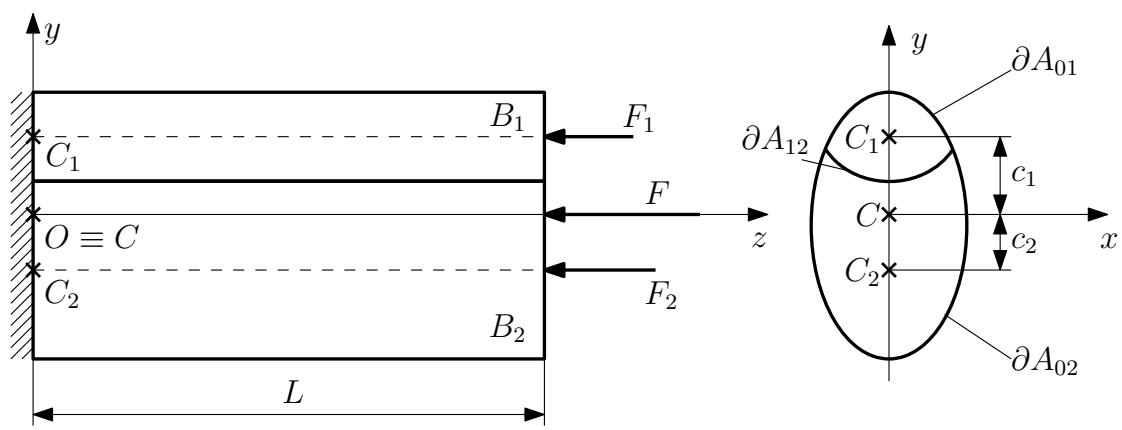

Figure 1. Two-layered beam with weak shear connection

$\partial A_{i}=\partial A_{0 i} \cup \partial A_{12},(i=1,2)$ (Figure 1). Here $L$ is the length of the beam and $\partial A_{0 i}$ is the 'outer' boundary curve of the cross-section $A_{i}(i=1,2)$. A point $P$ in $\bar{B}=B \cup \partial B\left(\partial B=\left(\partial A_{01} \cup \partial A_{02}\right) \times[0, L]\right)$ is determined by the position vector $\mathbf{r}=x \mathbf{e}_{x}+y \mathbf{e}_{y}+z \mathbf{e}_{z}$, where $x, y, z$ and $\mathbf{e}_{x}, \mathbf{e}_{y}, \mathbf{e}_{z}$ are referred to the rectangular coordinate system $O x y z$ shown in Figure 11. The axis $z$ is located in the $E$-weighted centerline of the whole composite beam and the plane $y z$ is the plane of symmetry for the geometrical and support conditions. The center of $A_{i}$ is $C_{i}(i=1,2)$ and $C$ is the $E$-weighted center of the whole cross-section $A=A_{1} \cup A_{2}$ (Figure 1), furthermore

$$
c_{1}=\left|\overrightarrow{C C_{1}}\right|, \quad c_{2}=\left|\overrightarrow{C C_{2}}\right| .
$$

According to the Euler-Bernoulli beam theory the displacement field $\mathbf{u}=u \mathbf{e}_{x}+v \mathbf{e}_{y}+$ $w \mathbf{e}_{z}$ has the form 6

$$
\begin{gathered}
u=0, \quad v=v(z, t), \quad \tilde{w}_{i}(y, z, t)=-\frac{F}{\langle A E\rangle} z+w_{i}(z, t)-y \frac{\partial v}{\partial z}, \\
(x, y, z) \in B_{i}, \quad(i=1,2),
\end{gathered}
$$

where $\langle A E\rangle=A_{1} E_{1}+A_{2} E_{2}$ and $t$ is the time. Application of the strain-displacement relationship of elasticity and Hooke's law gives

$$
\sigma_{z i}=E_{i} \varepsilon_{i}=E_{i} \frac{\partial \tilde{w}_{i}}{\partial z}=E_{i}\left(-\frac{F}{\langle A E\rangle}+\frac{\partial w_{i}}{\partial z}-y \frac{\partial^{2} v}{\partial z^{2}}\right), \quad(i=1,2) .
$$

The definition of section axial forces provides

$$
\begin{aligned}
\tilde{N}_{i}=\int_{A_{i}} \sigma_{z i} \mathrm{~d} A & =-F \frac{A_{i} E_{i}}{\langle A E\rangle}+A_{i} E_{i} \frac{\partial w_{i}}{\partial z}+(-1)^{i} c_{i} A_{i} E_{i} \frac{\partial^{2} v}{\partial z^{2}}= \\
& =-F \frac{A_{i} E_{i}}{\langle A E\rangle}+N_{i}, \quad(i=1,2) .
\end{aligned}
$$

The mechanical meaning of the first term in the expression of $\tilde{N}_{i}$ is as follows (see Figure 1)

$$
F_{i}=\frac{A_{i} E_{i}}{\langle A E\rangle} F, \quad(i=1,2), \quad F=F_{1}+F_{2} .
$$



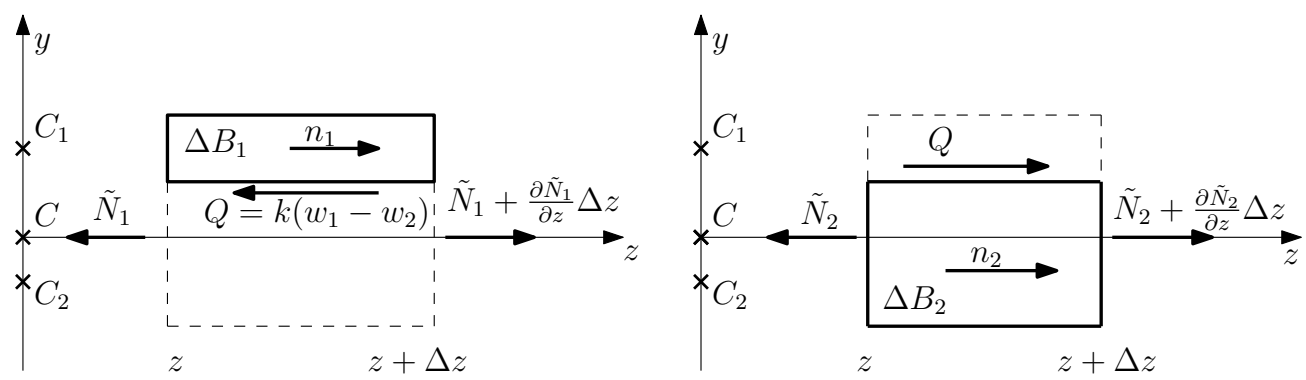

Figure 2. Free body diagram for axial forces

The axial force function in the whole beam

$$
N=\tilde{N}_{1}+\tilde{N}_{2}=-F+N_{1}+N_{2}=-F .
$$

According to this we have

$$
N_{1}+N_{2}=A_{1} E_{1}\left(\frac{\partial w_{1}}{\partial z}-c_{1} \frac{\partial^{2} v}{\partial z^{2}}\right)+A_{2} E_{2}\left(\frac{\partial w_{2}}{\partial z}+c_{2} \frac{\partial^{2} v}{\partial z^{2}}\right)=0 .
$$

The moment of normal stress $\sigma_{z}$ about axis $x$ is expressed as

$$
\begin{aligned}
M & =\tilde{M}_{1}+\tilde{M}_{2}=\int_{A_{1}} y \sigma_{z 1} \mathrm{~d} A+\int_{A_{2}} y \sigma_{z 2} \mathrm{~d} A= \\
& =E_{1} A_{1} c_{1} \frac{\partial w_{1}}{\partial z}-E_{2} A_{2} c_{2} \frac{\partial w_{2}}{\partial z}-\{I E\} \frac{\partial^{2} v}{\partial z^{2}},
\end{aligned}
$$

where

$$
\{I E\}=I_{1} E_{1}+I_{2} E_{2}, \quad I_{i}=\int_{A_{i}} y^{2} \mathrm{~d} A, \quad(i=1,2) .
$$

Denote $Q$ the interlayer shear force. The interlayer slip is interpreted as the difference of the axial displacements of the layers $\left(w_{1}-w_{2}\right)$ so we have for the interlayer shear force

$$
Q=k\left(w_{1}-w_{2}\right)
$$

Here, $k$ is the so-called slip modulus, which characterizes the rigidity of the connection. When the value of $k$ is equal to zero $(Q=0)$ there is no connection between the layers. If the slip modulus is equal to infinity $\left(w_{1}-w_{2}=0\right)$ the connection among the layers is perfect.

The beam elements $\Delta B_{1}$ and $\Delta B_{2}$ assigned by $z$ and $z+\Delta z$ coordinates are shown in Figure 2 The force equilibrium equations in axial direction for beam component $\Delta B_{1}$ and $\Delta B_{2}$ can be written in the form

$$
\begin{aligned}
& \frac{\partial \tilde{N}_{1}}{\partial z}+n_{1}-k\left(w_{1}-w_{2}\right)=0 \\
& \frac{\partial \tilde{N}_{2}}{\partial z}+n_{2}+k\left(w_{1}-w_{2}\right)=0
\end{aligned}
$$




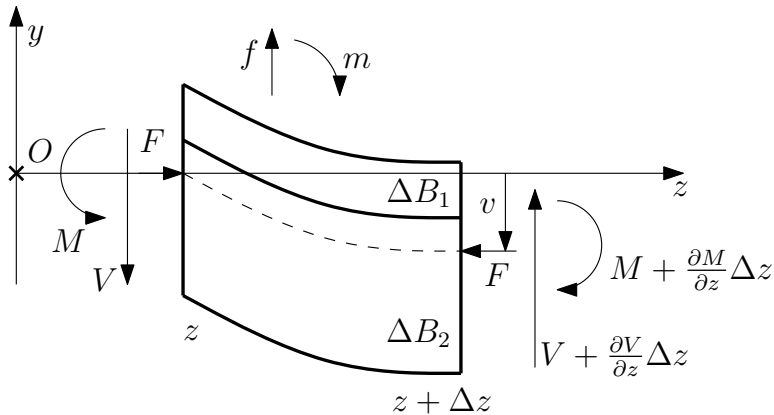

Figure 3. A small beam element $\Delta B_{1} \cup \Delta B_{2}$ with the shear forces and bending moments

The applied line loads in axial direction are denoted by $n_{1}$ and $n_{2}$. A $\Delta B_{1} \cup \Delta B_{2}$ beam element is illustrated in Figure 3 without the axial forces. According to this beam element the following equilibrium equations can be deduced

$$
\frac{\partial V}{\partial z}+f=0, \quad \frac{\partial M}{\partial z}+F \frac{\partial v}{\partial z}-V+m=0 .
$$

In equation (13) $f=f(z, t)$ is the applied line load, $V=V(z, t)$ is the shear force, $m$ is the applied distributed moment. From equation (13) the shear force can be eliminated. In this way we obtain only one equilibrium equation instead of the two in equation 13

$$
\frac{\partial^{2} M}{\partial z^{2}}+F \frac{\partial^{2} v}{\partial z^{2}}+\frac{\partial m}{\partial z}+f=0
$$

In equations (11), 12, 13 and (14) furthermore in Figures 2 and 3 the d'Alembert forces are introduced in the next form

$$
\begin{gathered}
f(z, t)=-\left(\rho_{1} A_{1}+\rho_{2} A_{2}\right) \frac{\partial^{2} v}{\partial t^{2}} \\
n_{1}(z, t)=-\rho_{1} A_{1} \frac{\partial^{2} w_{1}}{\partial t^{2}}+c_{1} \rho_{1} A_{1} \frac{\partial^{3} v}{\partial z \partial t^{2}} \\
n_{2}(z, t)=-\rho_{2} A_{2} \frac{\partial^{2} w_{2}}{\partial t^{2}}-c_{2} \rho_{2} A_{2} \frac{\partial^{3} v}{\partial z \partial t^{2}} \\
m(z, t)=-c_{1} \rho_{1} A_{1} \frac{\partial^{2} w_{1}}{\partial t^{2}}+c_{2} \rho_{2} A_{2} \frac{\partial^{2} w_{2}}{\partial t^{2}}+\{\rho I\} \frac{\partial^{3} v}{\partial z \partial t^{2}} .
\end{gathered}
$$

Here, $\rho_{1}$ and $\rho_{2}$ mean the mass density of beam component $B_{1}$ and $B_{2}$, respectively, and

$$
\{\rho I\}=\rho_{1} I_{1}+\rho_{2} I_{2} .
$$

Combining equations (4), (8), (11), 12) and (14) with equations 15 18 yields the system of motion equations for the two-layered composite beam with interlayer slip

$$
E_{1} A_{1} \frac{\partial^{2} w_{1}}{\partial z^{2}}-c_{1} E_{1} A_{1} \frac{\partial^{3} v}{\partial z^{3}}-k\left(w_{1}-w_{2}\right)-\rho_{1} A_{1} \frac{\partial^{2} w_{1}}{\partial t^{2}}+c_{1} \rho_{1} A_{1} \frac{\partial^{3} v}{\partial z \partial t^{2}}=0
$$




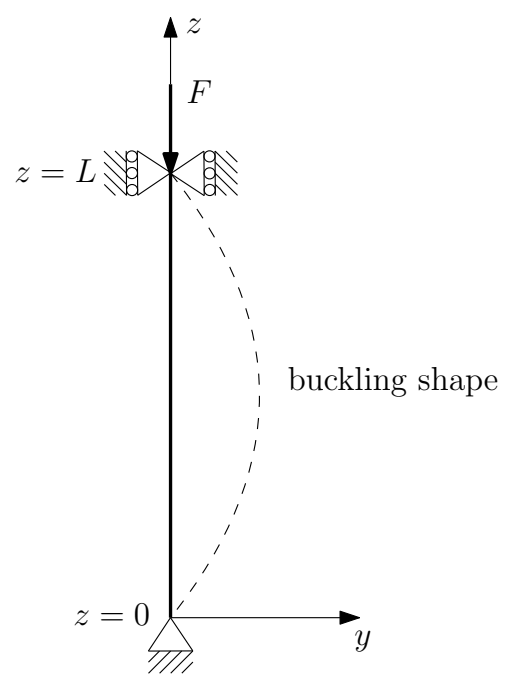

Figure 4. Simply supported column with axial load and its buckling shape

$$
\begin{gathered}
E_{2} A_{2} \frac{\partial^{2} w_{2}}{\partial z^{2}}+c_{2} E_{2} A_{2} \frac{\partial^{3} v}{\partial z^{3}}+k\left(w_{1}-w_{2}\right)-\rho_{2} A_{2} \frac{\partial^{2} w_{2}}{\partial t^{2}}-c_{2} \rho_{2} A_{2} \frac{\partial^{3} v}{\partial z \partial t^{2}}=0 \\
c_{1} E_{1} A_{1} \frac{\partial^{3} w_{1}}{\partial z^{3}}-c_{2} E_{2} A_{2} \frac{\partial^{3} w_{2}}{\partial z^{3}}-\{I E\} \frac{\partial^{4} v}{\partial z^{4}}+F \frac{\partial^{2} v}{\partial z^{2}}-c_{1} \rho_{1} A_{1} \frac{\partial^{3} w_{1}}{\partial z \partial t^{2}}+ \\
+c_{2} \rho_{2} A_{2} \frac{\partial^{3} w_{2}}{\partial z \partial t^{2}}+\{\rho I\} \frac{\partial^{4} v}{\partial z^{2} \partial t^{2}}-\left(\rho_{1} A_{1}+\rho_{2} A_{2}\right) \frac{\partial^{2} v}{\partial t^{2}}=0
\end{gathered}
$$

\section{Simply SUPPORTED BEAM-COLUMN}

The considered simply supported column is shown in Figure 4 . In this case the following boundary conditions are valid:

$$
\begin{gathered}
N_{1}(0, t)=N_{1}(L, t)=0, \quad t>0, \\
N_{2}(0, t)=N_{2}(L, t)=0, \quad t>0, \\
M(0, t)=M(L, t)=0, \quad t>0, \\
v(0, t)=v(L, t)=0, \quad t>0 .
\end{gathered}
$$

We look for the solution of the boundary value problem 20,22 and 23,26 in the following form:

$$
\begin{gathered}
w_{1}(z, t)=W_{1 j} \cos \frac{j \pi}{L} z \cos \omega_{j} t, \\
w_{2}(z, t)=W_{2 j} \cos \frac{j \pi}{L} z \cos \omega_{j} t, \\
v(z, t)=V_{j} \sin \frac{j \pi}{L} z \cos \omega_{j} t, \quad(j=1,2, \ldots) .
\end{gathered}
$$




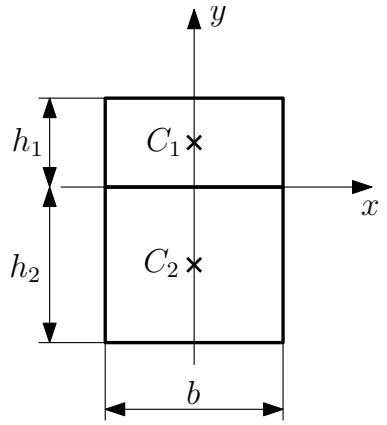

Figure 5. The cross section of the column considered in the example

These functions satisfy the boundary conditions $\sqrt{23} 26$ for all values of $W_{1 j}, W_{2 j}$, $V_{j}$. Substituting the functions into equations $20 \mid 22$ the following linear system of equation can be deduced:

$$
\mathbf{C}_{j} \mathbf{X}_{j}=\omega_{j}^{2} \mathbf{M}_{j} \mathbf{X}_{j}
$$

where

$$
\begin{gathered}
\mathbf{C}_{j}=\left[\begin{array}{ccc}
E_{1} A_{1}\left(\frac{j \pi}{L}\right)^{2}+k & -k & \left.-W_{1} E_{1} A_{1}\left(\frac{j \pi}{L}\right)^{3}, W_{2 j}, V_{j}\right]^{T}, \\
-k & E_{2} A_{2}\left(\frac{j \pi}{L}\right)^{2}+k & c_{2} E_{2} A_{2}\left(\frac{j \pi}{L}\right)^{3} \\
-c_{1} E_{1} A_{1}\left(\frac{j \pi}{L}\right)^{3} & c_{2} E_{2} A_{2}\left(\frac{j \pi}{L}\right)^{3} & \{I E\}\left(\frac{j \pi}{L}\right)^{4}-F\left(\frac{j \pi}{L}\right)^{2}
\end{array}\right], \\
\mathbf{M}_{j}=\left[\begin{array}{ccc}
\rho_{1} A_{1} & 0 & -c_{1} \rho_{1} A_{1} \frac{j \pi}{L} \\
0 & \rho_{2} A_{2} & -c_{2} \rho_{2} A_{2} \frac{j \pi}{L} \\
-c_{1} \rho_{1} A_{1} \frac{j \pi}{L} & -c_{2} \rho_{2} A_{2} \frac{j \pi}{L} & \{\rho I\}\left(\frac{j \pi}{L}\right)^{4}+\rho_{1} A_{1}+\rho_{2} A_{2}
\end{array}\right] .
\end{gathered}
$$

The non-trivial solution of equations $\sqrt{30}$ is sought that means

$$
\operatorname{det}\left(\mathbf{C}_{j}-\omega_{j}^{2} \mathbf{M}_{j}\right)=0, \quad(j=1,2, \ldots) .
$$

From equation (34) a cubic equation can be formulated for $\omega_{j}^{2}(j=1,2, \ldots)$ in terms of $F$, which means that we have three eigenfrequencies for each value of $j$ for arbitrary value of the axial load.

\section{NumERICAL EXAMPLE}

In this example the simply supported beam illustrated in Figure 4 is considered and its cross section is shown in Figure 5. The following data were used: $h_{1}=0.02 \mathrm{~m}$, $h_{2}=0.04 \mathrm{~m}, b=0.03 \mathrm{~m}, L=2 \mathrm{~m}, E_{1}=10^{10} \mathrm{~Pa}, E_{2}=2 \times 10^{11} \mathrm{~Pa}, k=10^{6} \mathrm{~Pa}$, $\rho_{1}=4000 \mathrm{~kg} / \mathrm{m}^{3}, \rho_{2}=7000 \mathrm{~kg} / \mathrm{m}^{3}$.

Substituting the data into equation (34) the eigenfrequencies were investigated for three different value of axial force. The results are shown in Table 1 for $F=0$, in Table 2 for $F=40,000 \mathrm{~N}$ and in Table 3 for $F=80,000 \mathrm{~N}$. According to the results one can see that by increasing the axial load the eigenfrequencies decreases. 
Table 1. The eigenfrequencies of simply supported column without axial force $(F=0)$

\begin{tabular}{|c|c|c|c|}
\hline$j$ & $\omega_{j 1} 1 / \mathrm{s}$ & $\omega_{j 2} 1 / \mathrm{s}$ & $\omega_{j 3} 1 / \mathrm{s}$ \\
\hline \hline 1 & 135.42 & 2566.01 & 8403.41 \\
\hline 2 & 539.36 & 5009.04 & 16796.21 \\
\hline 3 & 1211.79 & 7478.84 & 25191.61 \\
\hline 4 & 2151.61 & 9955.53 & 33587.91 \\
\hline 5 & 3357.32 & 12434.99 & 41984.87 \\
\hline 10 & 13289.8 & 24844.86 & 83980.52 \\
\hline
\end{tabular}

Table 2. The eigenfrequencies of simply supported column with axial force $F=40,000 \mathrm{~N}$

\begin{tabular}{|c|c|c|c|}
\hline$j$ & $\omega_{j 1} 1 / \mathrm{s}$ & $\omega_{j 2} 1 / \mathrm{s}$ & $\omega_{j 3} 1 / \mathrm{s}$ \\
\hline \hline 1 & 95.93 & 2566.01 & 8403.41 \\
\hline 2 & 504.36 & 5009.04 & 16796.21 \\
\hline 3 & 1177.49 & 7478.84 & 25191.61 \\
\hline 4 & 2117.52 & 9955.53 & 33587.91 \\
\hline 5 & 3323.33 & 12434.99 & 41984.87 \\
\hline 10 & 13256.3 & 24844.86 & 83980.51 \\
\hline
\end{tabular}

Table 3. The eigenfrequencies of simply supported column with axial force $F=80,000 \mathrm{~N}$

\begin{tabular}{|c|c|c|c|}
\hline$j$ & $\omega_{j 1} 1 / \mathrm{s}$ & $\omega_{j 2} 1 / \mathrm{s}$ & $\omega_{j 3} 1 / \mathrm{s}$ \\
\hline \hline 1 & 8.167 & 2566.01 & 8403.41 \\
\hline 2 & 466.78 & 5009.04 & 16796.21 \\
\hline 3 & 1142.08 & 7478.84 & 25191.61 \\
\hline 4 & 2082.86 & 9955.53 & 33587.91 \\
\hline 5 & 3289.01 & 12434.99 & 41984.87 \\
\hline 10 & 13222.73 & 24844.86 & 83980.51 \\
\hline
\end{tabular}

The relation between the axial force and the square of the eigefrequency is a linear relationship. Applying the presented method a linear function is provided that is illustrated below. Figures 6, 7, 8, 9, 10, and 11, show the connection between the axial force and the square of the eigenfrequency for $j=1, j=2, j=3, j=4, j=5$ and $j=10$, respectively. When the axial load is equal to zero the method gives the same eigenfrequencies (Table 1) as in an earlier study by Lengyel and Ecsedi [18. In [18] the authors proposed an analytical method for the free vibration of a composite beam with interlayer slip without any loading. 


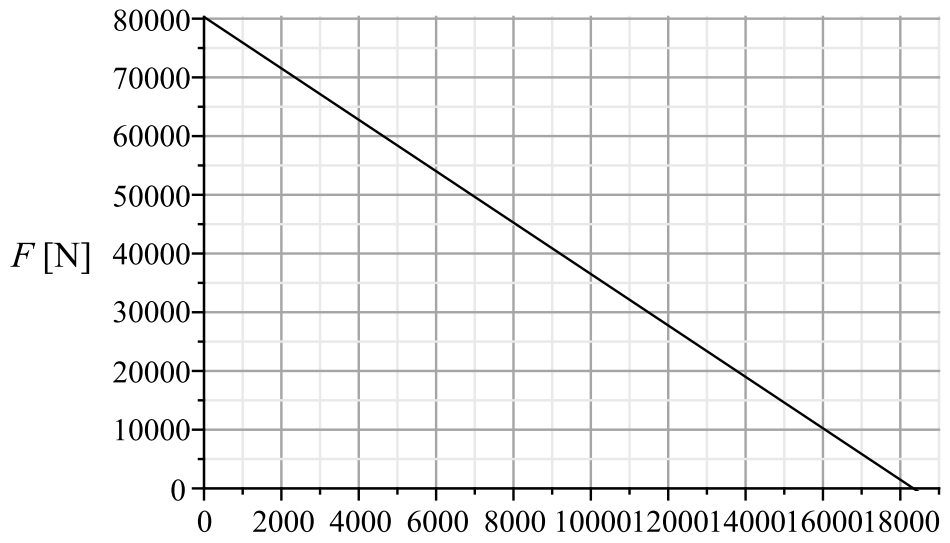

$\omega_{11}^{2}\left[\frac{1}{s^{2}}\right]$

Figure 6. The function of $F=F\left(\omega_{11}^{2}\right)$

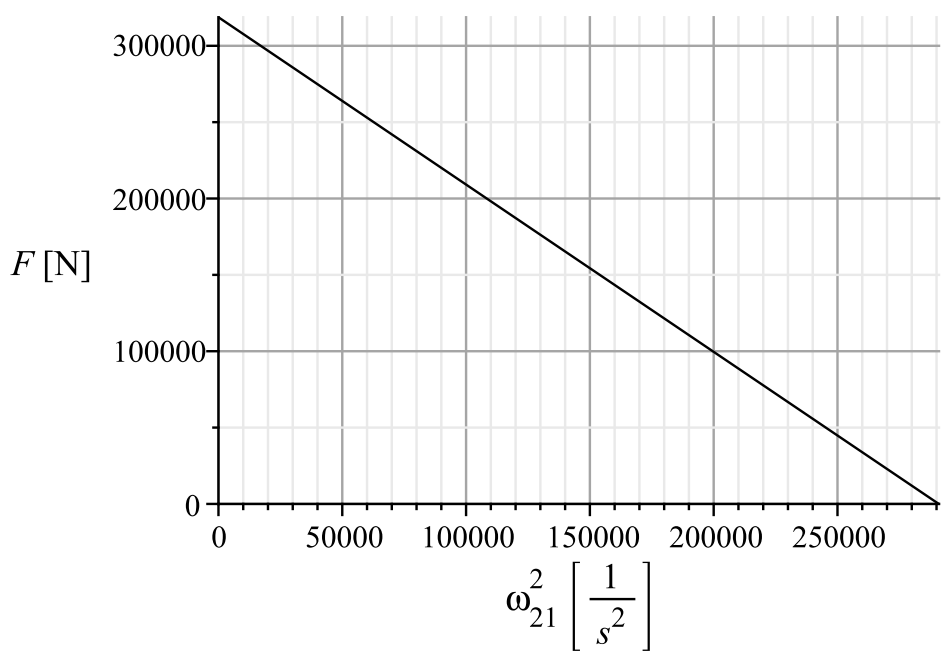

Figure 7. The function of $F=F\left(\omega_{21}^{2}\right)$

If the $j$-th eigenfrequency is equal to zero the $j$-th critical load can be gained from the presented method. Lengyel and Ecsedi in [17] deduced a solution method for determination of the critical buckling load of composite beams with interlayer slip. During the analysis they derived a closed form for the $j$-th critical load, which is 


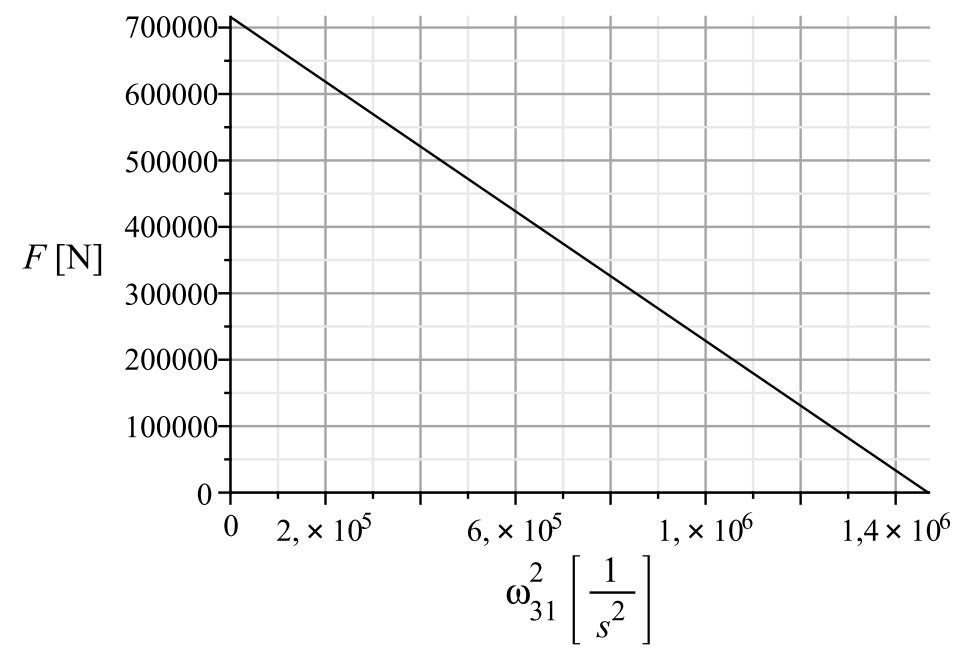

Figure 8. The function of $F=F\left(\omega_{31}^{2}\right)$

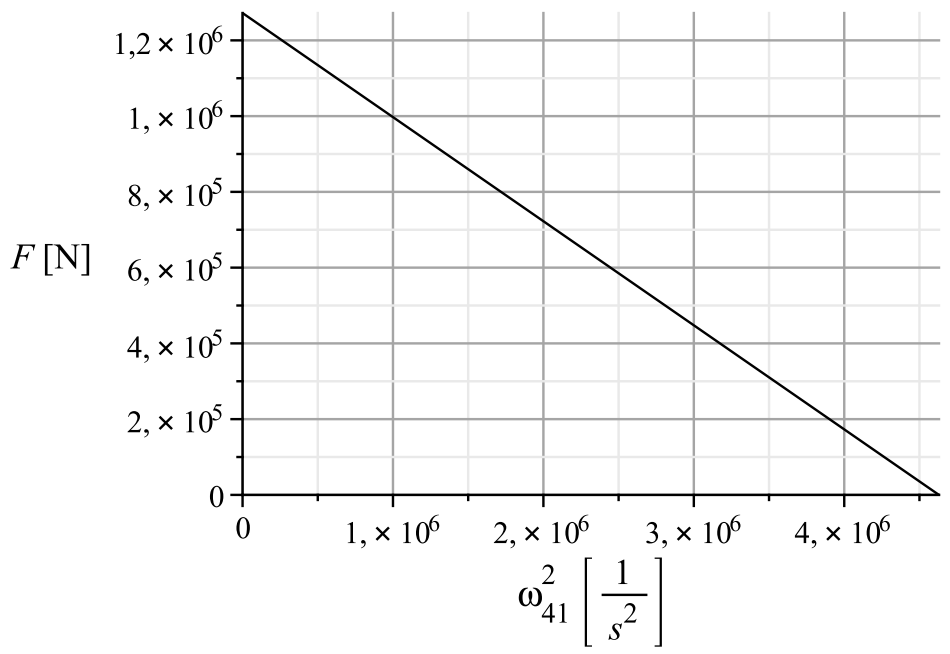

Figure 9. The function of $F=F\left(\omega_{41}^{2}\right)$

$$
F_{j}^{c r}=\frac{\langle I E\rangle\langle A E\rangle_{-1}\left(\frac{j \pi}{L}\right)^{4}+k\{I E\}\left(\frac{j \pi}{L}\right)^{2}}{\langle A E\rangle_{-1}\left(\frac{j \pi}{L}\right)^{2}+k} .
$$

Here,

$$
\langle A E\rangle_{-1}=\frac{A_{1} E_{1} A_{2} E_{2}}{A_{1} E_{1}+A_{2} E_{2}},
$$




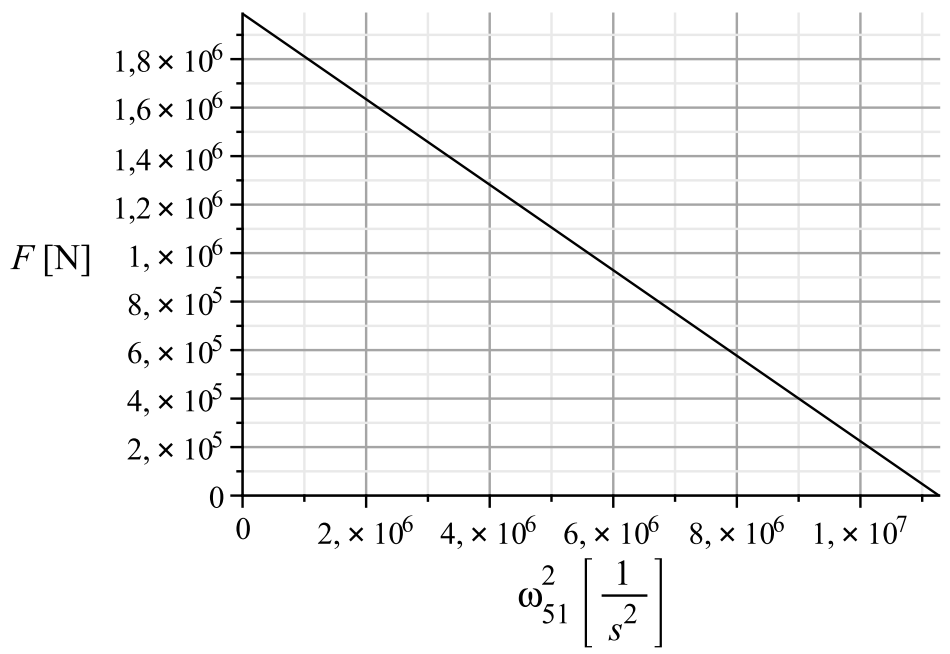

Figure 10. The function of $F=F\left(\omega_{51}^{2}\right)$

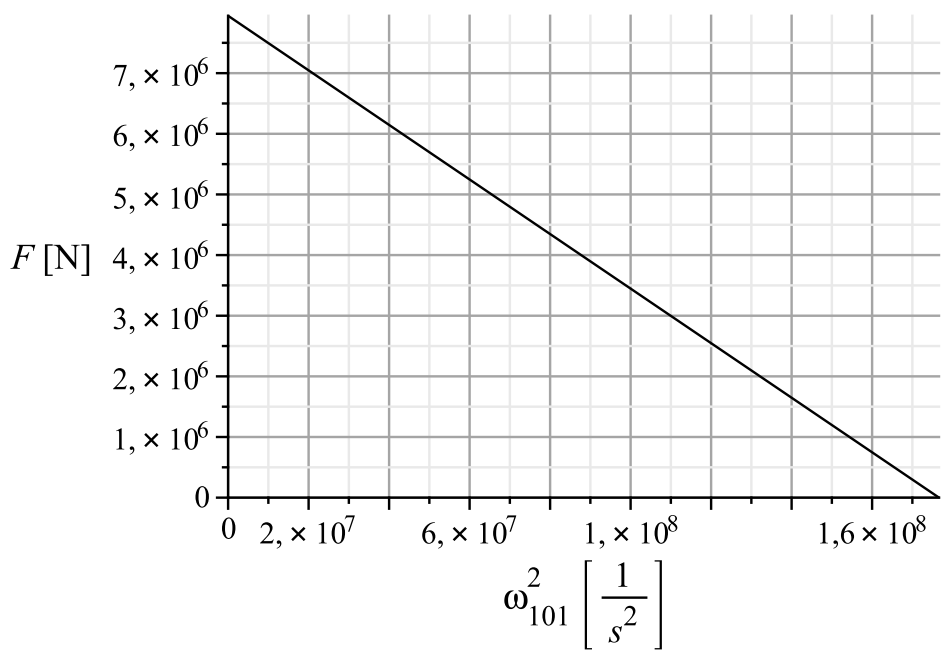

Figure 11. The function of $F=F\left(\omega_{101}^{2}\right)$

$$
\langle I E\rangle=\{I E\}-c^{2}\langle A E\rangle_{-1}, \quad c=c_{1}+c_{2} .
$$

Table 4 illustrates the $j$-th critical load from the presented method and computed by equation (35). 
Table 4. The critical loads for the simply supported composite beam with interlayer slip.

\begin{tabular}{|c|c|c|}
\hline$j$ & $F_{j}^{c r}[\mathrm{~N}]$ from equation $(34), \omega_{j}=0$ & $F_{j}^{c r}[\mathrm{~N}]$ from equation $[35)$ \\
\hline \hline 1 & $80,292.038$ & $80,292.038$ \\
\hline 2 & $318,685.949$ & $318,685.949$ \\
\hline 3 & $715,945.968$ & $715,945.968$ \\
\hline 4 & $1,272,101.169$ & $1,272,101.17$ \\
\hline 5 & $1,987,155.398$ & $1,987,155.402$ \\
\hline 10 & $7,945,930.916$ & $7,945,930.923$ \\
\hline
\end{tabular}

\section{Conclusions}

The paper proposes a new analytical method for the analysis of free vibration of composite beams with interlayer slip loaded by axial force. The presented method takes into account the influence of axial and rotary inertia, from which three different eigenfrequencies can be obtained for each value of $j$. The connection between the axial force and the square of the eigenfrequency is linear. The critical buckling loads and the eigenfrequencies belonging to the composite beam without axial loading are also computed by means of the method and the results are in very good agreement with the results from earlier studies.

Acknowledgement. Supported by the ÚNKP-16-3. New National Excellence Program of the Ministry of Human Capacities.

\section{REFERENCES}

1. Newmark, N. M., Siess, C. P., and Viest, I. M.: Test and analyis of composite beams with incomplete interaction. Proceedings of the Society of Experimental Stress Analysis, 9(1), (1951), 75-92.

2. STÜssi, F.: Zusammengesetzte Vollwandträger. IABSE Publications, 8, (1947), 249-269.

3. Granholm, H.: On composite beams and columns with particular regard to nailed timber structures. Transaction No. 88, Chalmers Technical University, Göteborg, Sweden, 1949. (in Swedish).

4. KovÁcs, B.: Vibration of multi-layered bands with interfacial imperfection. Journal of Sound and Vibration, 300(1-2), (2007), 379-386.

5. Girhammar, U. A. and Gopu, V. K. A.: Composite beam-columns with interlayer slip - exact analysis. Journal of Structural Engineering, 119(4), (1993), 1265-1282.

6. ECSEDI, I. and BAKSA, A.: Static analysis of composite beams with weak shear connection. Applied Mathematical Modelling, 35(4), (2011), 1739-1750.

7. Girhammar, U. A. and Pan, D.: Dynamic analysis of composite members with interlayer slip. International Journal of Solids and Structures, 30(6), (1993), 797-823.

8. Adam, C., Heuer, R., and Jeschko, A.: Flexural vibrations of elastic composite beams with interlayer slip. Acta Mechanica, 125(1), (1997), 17-30. 
9. Heuer, R. and Adam, C.: Piezoelectric vibrations of composite beams with interlayer slip. Acta Mechanica, 140(3), (2000), 247-263.

10. Girhammar, U. A., Pan, D. H., and Gustafsson, A.: Exact dynamic analysis of composite beams with partial interaction. International Journal of Mechanical Sciences, 51(8), (2009), 565-582.

11. Wu, Y. F., Xu, R., and Chen, W.: Free vibrations of the partial-interaction composite members with axial force. Journal of Sound and Vibration, 299(4-5), (2007), 1074-1093.

12. Challamel, N. and Girhammar, U. A.: Lateral-torsional buckling of vertically layered composite beams with interlayer slip under uniform moment. Engineering Structures, 34(8), (2012), 505-513.

13. Chen, F. and Qiao, P.: Buckling of delaminated bi-layer beam-columns. International Journal of Solids and Structures, 48(18), (2011), 2485-2495.

14. Grognec, P. L., Nguyen, Q. H., and HJiaj, M.: Exact buckling solution for two-layer Timoshenko beams with interlayer slip. International Journal of Solids and Structures, 49(1), (2012), 143-150.

15. Schnabl, S. and Planinc, I.: The influence of boundary conditions and axial deformability on buckling behavior of two-layer composite columns with interlayer slip. Engineering Structures, 32(10), (2010), 3103-3111.

16. Schnabl, S. and Planinc, I.: The effect of transverse shear deformation on the buckling of two-layer composite columns with interlayer slip. International Journal of Non-Linear Mechanics, 46(3), (2011), 543-553.

17. Lengyel, A. J. and Ecsedi, I.: Elastic stability of columns with weak shear connection. In MultiScience - XXVIII. microCAD International Multidisciplinary Scientific Conference, Miskolc, Hungary, University of Miskolc, 2014. Paper no. D-37.

18. Lengyel, A. J. and Ecsedi, I.: Kétrétegű nem tökéletesen kapcsolt kompozit rudak rezgéseinek vizsgálata GÉP, LXV(1), (2014), 34-38. (in Hungarian). 